\title{
Proarrhytmic effect of amiodarone can cause "electrical storm" in patient with ischaemic cardiomyopathy and implantable cardioverter defibrillator
}

\author{
Petra Angebrandt*, Karlo Golubić, Anton Šmalcelj \\ University of Zagreb School of Medicine, University Hospital Centre Zagreb, Zagreb, Croatia
}

The goal: Electrical storm (ES) is a life-threatening syndrome that involves recurrent episodes of ventricular arrhythmias. Data on its prognostic significance strongly suggest that these patients have a poor outcome and had an increased risk of non-sudden cardiac death. The goal of this case report is to show the importance of clinical judgment in the treatment of post myocardial arrhythmia in complex patients, such as those with an implantable cardioverter defibrillator (ICD).

Case presentation: A 61-year-old male patient experienced sustained ventricular tachycardia after myocardial infarction. Due to severely impaired left ventricular function, he underwent maximal medical treatment for heart failure together with amiodarone and ICD implantation. Following ICD implantation, he presented with ES and we noticed a prolongation of the QT interval in ECG. We excluded amiodarone because of the evident proarrhythmic effect. During hospi-

Received: $30^{\text {th }}$ Apr 2014

*Address for correspondence: Klinički bolnički centar Zagreb, Kišpatićeva 12, HR10000 Zagreb, Croatia.

Phone: +385-91-1596-814

E-mail: petraang37@yahoo.com talization and in outpatient follow-up, we detected no ventricular tachycardia, neither in ECG monitoring, nor in the ICD device record. In the one month follow-up we detected normalization of the QT interval. However, after 9 months, the patient experienced VT episodes and one of them was terminated by ICD shock. This event was complicated by head trauma and subsequent subdural hematoma and posttraumatic subarachnoid hemorrhage. The patient underwent urgent neurocranial surgery. Unfortunately, the patient died on the third day after the surgery.

Conclusion: Cardiac mortality of patients with all types of ventricular tachyarrhythmias is high. The use of antiarrhytmic agents may predispose the patient to proarrhythmic complications that might pose a significant threat to life. Though amiodarone has become the first line drug to treat ventricular tachyarrhythmias in patients with cardiac dysfunction, it is important to be aware of its proarrhythmic effect, which may lead to an ES of monomorphic VT. Druginduced effects on the QT interval with the associated possibility of inducing fatal arrhythmias have become a new challenge for the practitioner, the drug development process and the regulatory agencies.

KEYWORDS: electrical storm, amiodarone, proarrhytmic effect.

CITATION: Cardiol Croat. 2014;9(5-6):211.

\section{Literature}

1. Eifiling M, Razavi M, Massumi A. The evaluation and manangement of electrical storm.Tex Heart Inst J. 2011;38(2):111-21.

2. Emkanjoo Z, Alihasani N, Alizadeh A, et al. Electrical storm in patients with implantable cardioverter-defibrillators: can it be forecast? Tex Heart Inst J. 2009;36(6):563-7.

3. Hohnloser SH, Klingenheben T, Singh BN. Amiodarone-associated proarrhythmic effects. A review with special reference to torsade de pointes tachycardia. Ann Intern Med. 1994;121(7):529-35. 